\title{
Authors' Selection of Target Journals and Their Attitudes to Emerging Journals A survey from two developing regions
}

Salem A. Beshyah

$$
\text { اختيارات المؤلفين للمجالات المستهدفة ومواقفهم من البحلات المستجدة }
$$

$$
\text { سالم العريفي بشيه }
$$

\begin{abstract}
Objectives: This study aimed to assess the factors that influence authors' decision when choosing a journal for publication and to assess authors' attitudes and practices regarding emerging journals. Methods: This cross-sectional questionnaire-based study was conducted between April and July 2017 at Dubai Medical College, Dubai, United Arab Emirates, on a convenience sample of 2,764 healthcare professionals. Results: A total of 250 responses were received (response rate: 9\%) and 152 valid respondents were included in this study (5.6\%), of which the majority were male (61.2\%) and aged 41-60 years (68\%) from the Middle East and Africa. Most respondents (88.8\%) had medical and/or dental qualifications and the majority were in senior clinical (55\%) and academic (71.5\%) positions. More than half of the respondents (62.5\%) had published at least one article in the previous five years. Results showed that journal impact factor (JIF), indexation status, free submission and being international were important among respondents. Based on the respondents that shared their encounters with emerging journals $(\mathrm{n}=114), 62$ respondents $(54.4 \%)$ regularly read certain emerging journals, $51(44.7 \%)$ had been a peer-reviewer, 48 (42.1\%) had cited content from an emerging journal at least once and 45 (39.5\%) had published in emerging journals. Only 18 respondents (14.2\%) were not convinced with the need for emerging journals and believed that all researchers should compete for publication in the same international journals. Conclusion: Selection of target journals is driven mainly by JIF, indexation status, free submission and a journal's international status. A diverse range of opinions and attitudes regarding emerging journals were observed in this study.
\end{abstract}

Keywords: Journal Impact Factor; Open Access Publishing; Editorial Policy; Peer Review; Indexing; Publications; Attitude; United Arab Emirates.

الملخص: الهدف: تقييم العوامل التي تؤثر على قرار المؤلفين عند اختيار مجلة للنثر ـ ثانياً: تقييم مواقف المؤلفين ومدارساتهم فيما

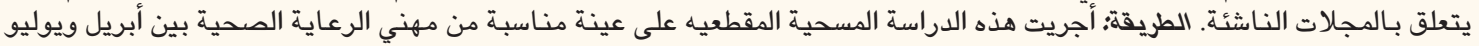

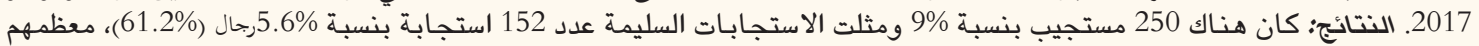

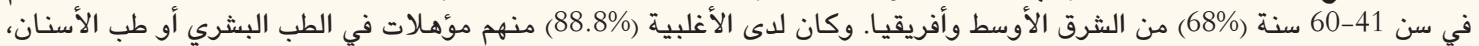

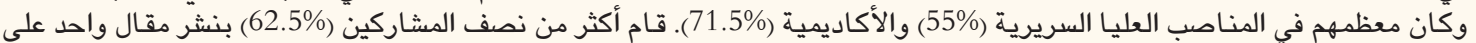

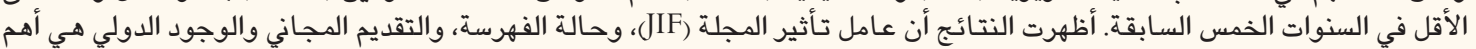

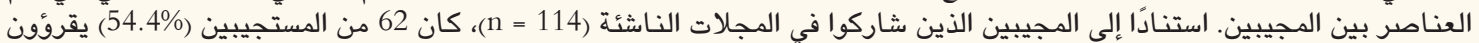

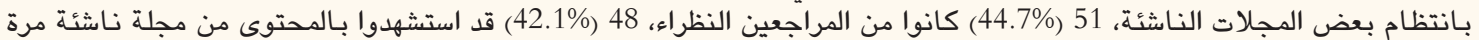

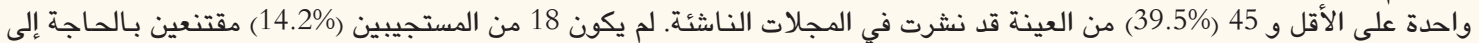

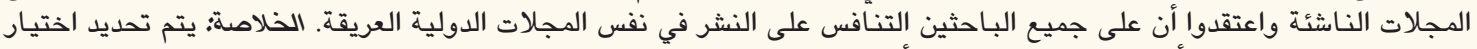

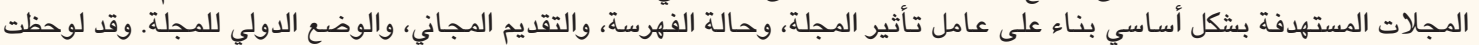

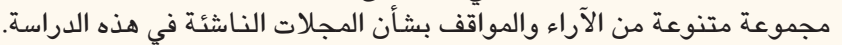

الكلمات المفتاحية: عامل تأثير مجلة؛ النثر المفتوح؛ سياسة التحرير؛ استعراض النظراء؛ الفهرسة؛ المنشورات؛ سلوك؛ الإمارات العربية المتحدة.

\section{Advances in KNOWLedge}

The main driving factors that influence the decisions of authors from the Middle East and Africa in choosing a target journal include the journal's impact factor, indexation status, possibility of free publication and the journal's international status.

Knowledge about perceptions of authors and their attitudes and practices towards emerging journals in developing regions provide crucial insight for regional editors and publishers to develop editorial strategies to meet the expectations of their readers and potential authors.

\section{Application to Patient Care}

Emerging journals provide a better platform for publishing peculiarities and challenges in diagnosis and management of patients in developing regions, which will aid local physicians to better manage their patients. 
$\mathrm{P}$ SICATION OF SCIENTIFIC RESEARCH REQUIRES selecting an appropriate topic, knowing the target journal and its readership, framing the article according to that journal's specific style and working with the journal's editorial team to create a publishable manuscript. ${ }^{1,2}$ In preparing a manuscript for submission, the research material should be structured and written in a style that conveys the authors' message with clarity. The authors' should match their research material to the most appropriate manuscript category and journal. ${ }^{3-5}$ Ideally, these choices should solely determine journal selection; however, journal selection may be influenced by other factors. ${ }^{5}$

In the current study, emerging journals are defined as non-profitable national and/or regional journals that report important and practical information of local/ regional importance. These are to be distinguished from predatory journals that seek to financially profit from authors without providing any standard scholarly publishing service for the authors or their readership. The main challenge for these journals is the potential lack of international visibility, such as not being indexed on main indexation systems like the PubMed ${ }^{\circledR}$ database (National Library of Medicine, Bethesda, Maryland, USA). This lack of visibility might result in smaller chances of being cited by other authors and result in a lower journal impact factor (JIF).

Several studies have examined the factors that influence authors' choice of target journal in Western countries, yet no similar data are available from developing countries. ${ }^{6-8}$ This information may be important to editors and publishers of emerging journals in developing regions. In addition, assessing the attitudes of authors from developing countries towards emerging journals is crucial for determining the level of their support of these journals., ${ }^{9,10}$ In choosing a target journal for publication, different factors may vary in importance depending on the authors' status and circumstances. ${ }^{11}$

In general, research and literature productivity of developing nations is low. ${ }^{12}$ Authors from low/middle income countries (LMIC) may have to choose between submitting to highly competitive international journals, unaffordable open access journals of high reputation or may inadvertently submit to predatory journals. ${ }^{13}$ To this end, several genuine open access journals have emerged in LMIC with the primary focus of mentoring and nurturing this group of authors. ${ }^{9,10}$ Knowing the attitudes of potential authors towards these journals is very useful to both editors and publishers. The present study is the first to address these two issues specifically from the Middle East and Africa. Therefore, this study aimed to, firstly, assess factors that influence the decision of authors from developing countries when choosing a journal for publication and secondly, to assess these authors' attitudes and practices regarding emerging journals.

\section{Methods}

This cross-sectional electronic questionnaire-based study was conducted between April and July 2017 at Dubai Medical College, Dubai, United Arab Emirates (UAE). For the creation, dissemination and analysis of the questionnaire, Survey Monkey ${ }^{\circledR}$ (SVMK Inc., San Mateo, California, USA) was used. The questionnaire was electronically sent to a convenience sample of 2,764 healthcare professionals primarily residing and practicing in the Middle East and Africa. The practicing physicians and academics were identified on academic databases of health-related bodies, professional groups and recent continuous professional development events (e.g. American Association of Clinical Endocrinologists Gulf Chapter annual meetings) and/or by virtue of their contribution to the medical literature in biomedical subjects. The questions aimed to capture the demographic, professional and academic characteristics of the respondents as well as the deciding factors for journal choice along with their attitudes and experiences with

Table 1: Questionnaire topics and questions for healthcare professionals to assess demographic, professional and academic characteristics and attitudes towards emerging journals
Item Question/topic
$1 \quad$ Eligibility and consent.
2,3 Region and country of usual residence and practice.
4,5 Field of primary qualification and the highest academic/ professional qualification.
6,7 Gender and age group.
8,9 Professional/career track and specialty.
10 The language of your professional communications/pub- lications.
11-13 Current professional grades and titles.
14 Research interests.
15 Did you publish in a medical or biomedical journal over the previous 5 years?
16 If your answer was "yes" to the previous question, please indicate the type of publication.
17 Where do you usually publish?
18 Please indicate the extent to which each of the 15 factors influences the decision to submit an original article to a journal for an initial submission.
19 Please indicate the extent to which each of the 15 factors influences the decision to submit an original article to a journal for a resubmission after a manuscript had been rejected elsewhere (same factors as in question 18).
20 Attitudes toward emerging journals (without considering your choices to items 17-19): If you are based in a devel- oping region/country, how supportive would you be to publish your work and/or peer review for emerging journal?
21 Current practices of authors to emerging journals

"Questions 2-13 aimed to define the demographic and professional characteristics of the respondents; questions 14-17 aimed to define current research and publishing activity; questions 18 and 19 aimed to define the factors infuencing journal choice for initial submissions and resubmissions of rejected articles and questions 20 and 21 aimed to explore the attitudes and practices of current and potential authors to emerging journals. 
Table 2: Demographic, professional and academic characteristics of healthcare professionals from the Middle East and Africa $(\mathrm{N}=152)$

\begin{tabular}{|c|c|}
\hline Characteristic & n (\%) \\
\hline \multicolumn{2}{|l|}{ Gender } \\
\hline Male & $93(61.2)$ \\
\hline Female & $59(38.8)$ \\
\hline \multicolumn{2}{|l|}{ Age groups in years } \\
\hline$<30$ & $6(3.9)$ \\
\hline $31-40$ & $20(13.2)$ \\
\hline $41-50$ & $58(38.2)$ \\
\hline $51-60$ & $45(29.6)$ \\
\hline$>60$ & $23(15.1)$ \\
\hline \multicolumn{2}{|l|}{ Region of usual residence and practice } \\
\hline Middle East & $122(80.3)$ \\
\hline Africa & $30(19.7)$ \\
\hline \multicolumn{2}{|l|}{ Countries of origin } \\
\hline United Arab Emirates & 58 \\
\hline Saudi Arabia & 25 \\
\hline Iraq, Libya or Qatar & 9 each \\
\hline Kuwait or Egypt & 7 each \\
\hline Pakistan & 5 \\
\hline Lebanon, Morocco or Oman & 3 each \\
\hline Algeria, Ethiopia, Iran, Nigeria or Sudan & 2 each \\
\hline Cameroon, Ghana, Syria or Tunisia & 1 each \\
\hline \multicolumn{2}{|l|}{ Primary qualification } \\
\hline Medical and dental & $135(88.8)$ \\
\hline Biomedical sciences & $9(5.9)$ \\
\hline Nursing & $5(3.3)$ \\
\hline Pharmacy & $3(2.0)$ \\
\hline \multicolumn{2}{|l|}{ Highest academic/professional qualification } \\
\hline Bachelor & $12(7.9)$ \\
\hline Master & $11(7.2)$ \\
\hline Doctorate & $63(41.4)$ \\
\hline Board certification or equivalent & $58(38.2)$ \\
\hline Diploma or certificate & $8(5.3)$ \\
\hline \multicolumn{2}{|l|}{ Career path } \\
\hline Clinical and scientific (i.e. healthcare delivery) & $107(70.7)$ \\
\hline Academic (i.e. full-time university staff) & $45(29.3)$ \\
\hline \multicolumn{2}{|l|}{ Clinical practice grades $(n=125)^{*}$} \\
\hline Consultant & $69(55.2)$ \\
\hline Specialist & $35(28.0)$ \\
\hline Junior & $21(16.8)$ \\
\hline \multicolumn{2}{|l|}{ Academic position $(\mathrm{n}=\mathbf{8 1}) *$} \\
\hline Professor & $27(33.3)$ \\
\hline Associate professor & $16(19.8)$ \\
\hline Assistant professor & $23(28.4)$ \\
\hline Lecturer & $9(11.1)$ \\
\hline Assistant lecturer & $6(7.4)$ \\
\hline \multicolumn{2}{|l|}{ Clinical specialty } \\
\hline Internal medicine and its subspecialties & $84(55.0)$ \\
\hline Biomedical sciences & $16(10.6)$ \\
\hline Paediatrics & $15(9.9)$ \\
\hline
\end{tabular}

$\begin{array}{lc}\text { Primary care } & 15(9.9) \\ \text { Women's health } & 9(6.0) \\ \text { Surgery } & 7(4.6) \\ \text { Other } & 6(4.0)\end{array}$

Language used in professional communication

English $124(81.5)$

Arabic 21 (13.9)

French $\quad 7(4.6)$

*Not mutually exclusive.

Table 3: Publishing experience of included healthcare professionals from the Middle East and Africa $(\mathrm{N}=152)$

$\begin{array}{lc}\text { Measure of experience } & \mathbf{n}(\%)^{*} \\ \text { Number of publications in the previous five years } & \\ \text { None } & 57(37.5) \\ 1-5 & 46(30.3) \\ 6-10 & 15(9.9) \\ 11-15 & 13(8.6) \\ >15 & 21(13.8) \\ \text { Article type of previous publications }{ }^{\dagger}(\mathbf{n}=\mathbf{9 6}) & \\ \text { Original research } & 8(83.3) \\ \text { Clinical case, vignette or quiz } & 41(42.7) \\ \text { Review article } & 25(26.0) \\ \text { Letter to the editor } & 16(16.7) \\ \text { Commentary, viewpoint or editorial } & 9(9.4) \\ \text { Journal type of previous publications }{ }^{\dagger}(\mathbf{n}=\mathbf{1 0 4}) & \\ \text { International journal } & 81(77.9) \\ \text { Regional journal } & 35(33.7) \\ \text { National journal } & 28(26.9)\end{array}$

"Percentage adjusted for the total number of respondents to each question. t'Percentages do not add up to $100 \%$ as some respondents may have chosen more than one option

emerging journals [Table 1]. Following the initial invitation, four reminders were sent with an interval of 2-3 weeks. As there was no pre-determined sample size, a convenient sampling technique was used based on the number of respondents who replied within the study period.

The responses of consenting healthcare professionals who had confirmed they were residing and practicing in the Middle East or Africa were included. Responses received from individuals residing and practicing outside these regions were excluded. All data were analysed anonymously. In order to determine the influencing factors for authors, their scores were calculated based on the following formula:

score $=(2 \times$ moderately important $)+(3 \times$ very important $)$

\section{[Equation 1]}

This formula was also used to calculate the differences between initial manuscript submission and resubmission after initial rejection (hereafter referred to as second submission). The differences between the resulting score was compared using a Wilcoxon signed-rank test 
Table 4: Summary of the score of responses to level of importance of various deciding factors that determine journal selection for initial submission and second submission after rejection $(\mathrm{N}=152)$

\begin{tabular}{|c|c|c|c|c|c|c|c|c|}
\hline \multirow{3}{*}{$\begin{array}{l}\text { Deciding factors } \\
\text { (numbers for responses at IS } \\
\text { and SS) }\end{array}$} & \multicolumn{6}{|c|}{ n (\%) } & \multicolumn{2}{|c|}{ Score ${ }^{*}$} \\
\hline & \multicolumn{2}{|c|}{ Unimportant } & \multicolumn{2}{|c|}{ Moderately important } & \multicolumn{2}{|c|}{ Very important } & \multirow[b]{2}{*}{ IS } & \multirow[b]{2}{*}{ SS } \\
\hline & IS & SS & IS & SS & IS & SS & & \\
\hline Prestige $(n=112 ; n=112)$ & $21(18.8)$ & $25(22.3)$ & $58(51.8)$ & $59(52.7)$ & $33(29.5)$ & $28(25)$ & 215 & 202 \\
\hline $\begin{array}{l}\text { Journal impact factor } \\
(\mathrm{n}=118 ; \mathrm{n}=118)\end{array}$ & $6(5.1)$ & $9(7.6)$ & $48(40.7)$ & $60(50.8)$ & $64(54.2)$ & $49(41.5)$ & 288 & 267 \\
\hline $\begin{array}{l}\text { Journal indexation status } \\
(\mathrm{n}=112 ; \mathrm{n}=111)\end{array}$ & $5(4.5)$ & $9(8.1)$ & $54(48.2)$ & $58(52.3)$ & $53(47.3)$ & $44(39.6)$ & 267 & 248 \\
\hline $\begin{array}{l}\text { Perceived as international } \\
(\mathrm{n}=119 ; \mathrm{n}=118)\end{array}$ & $13(10.9)$ & $19(16.1)$ & $58(48.7)$ & $54(45.8)$ & $48(40.3)$ & $45(38.1)$ & 260 & 243 \\
\hline $\begin{array}{l}\text { Rapidity of turn round } \\
(\mathrm{n}=114 ; \mathrm{n}=113)\end{array}$ & $12(10.5)$ & $18(15.9)$ & $62(54.4)$ & $64(56.6)$ & $40(35.1)$ & $31(27.4)$ & 244 & 221 \\
\hline $\begin{array}{l}\text { A good editor } \\
(\mathrm{n}=115 ; \mathrm{n}=111)\end{array}$ & $15(13)$ & $17(15.3)$ & $53(46.1)$ & $68(61.3)$ & $47(40.9)$ & $26(23.4)$ & 247 & 214 \\
\hline $\begin{array}{l}\text { Knowing the editors } \\
(\mathrm{n}=109 ; \mathrm{n}=110)\end{array}$ & $58(53.2)$ & $53(48.2)$ & $34(31.2)$ & $43(39.1)$ & $17(15.6)$ & $14(12.7)$ & 119 & 128 \\
\hline $\begin{array}{l}\text { Having published in the journal before } \\
(\mathrm{n}=114 ; \mathrm{n}=112)\end{array}$ & $26(22.8)$ & $28(25.0)$ & $58(50.9)$ & $54(48.2)$ & $30(26.3)$ & $30(26.8)$ & 206 & 198 \\
\hline $\begin{array}{l}\text { Recommendation of colleagues } \\
(\mathrm{n}=113 ; \mathrm{n}=108)\end{array}$ & $20(17.7)$ & $23(21.3)$ & $71(62.8)$ & $62(57.4)$ & $22(19.5)$ & $23(21.3)$ & 208 & 193 \\
\hline $\begin{array}{l}\text { Journal usually publishes articles on } \\
\text { the topic }(\mathrm{n}=115 ; \mathrm{n}=111)\end{array}$ & $8(7)$ & $10(9)$ & $68(59.1)$ & $67(60.4)$ & $39(33.9)$ & $34(30.6)$ & 253 & 236 \\
\hline $\begin{array}{l}\text { Size of journal circulation } \\
(\mathrm{n}=111 ; \mathrm{n}=113)\end{array}$ & $18(16.2)$ & $24(21.2)$ & $57(51.4)$ & $62(54.9)$ & $36(32.4)$ & $27(23.9)$ & 222 & 205 \\
\hline $\begin{array}{l}\text { Size of journal circulation and likely } \\
\text { readership }(n=112 ; n=107)\end{array}$ & $30(26.8)$ & $27(25.2)$ & $58(51.8)$ & $61(57)$ & $24(21.4)$ & $19(17.8)$ & 188 & 179 \\
\hline $\begin{array}{l}\text { Useful peer reviews and statistical } \\
\text { advice }(\mathrm{n}=111 ; \mathrm{n}=112)\end{array}$ & $15(13.5)$ & $13(11.6)$ & $58(52.3)$ & $68(60.7)$ & $38(34.2)$ & $31(27.7)$ & 230 & 229 \\
\hline $\begin{array}{l}\text { Free submission to authors } \\
(\mathrm{n}=117 ; \mathrm{n}=112)\end{array}$ & $15(12.8)$ & $15(13.4)$ & $53(45.3)$ & $51(45.5)$ & $49(41.9)$ & $46(41.1)$ & 253 & 240 \\
\hline Open access $(\mathrm{n}=111 ; \mathrm{n}=108)$ & $15(13.5)$ & $20(18.5)$ & $51(45.9)$ & $48(44.4)$ & $45(40.5)$ & 40 (37) & 237 & 216 \\
\hline
\end{tabular}

IS = Initial submission; $S S=$ Second submission

"Cumulative score was calculated from the 'moderately important' and 'very important' responses. Wilcoxon signed-ranks for two paired samples was used.

for paired samples with statistical significance set at $P<0.01$.

All respondents provided electronic informed consent before answering the questionnaire. Any unwilling respondents had the option to be completely removed from the study and from receiving further invitation reminders. Ethical approval was granted by the Institutional Review Board of Sheikh Khalifa Medical City, Abu Dhabi, UAE (\#REC-13.08.2017 [RS-502]).

\section{Results}

A total of 250 responses were received (total response rate: $9 \%$ ) and 152 valid responses were included in this study (5.6\%). A total of 152 respondents were included in this study with more male than female respondents (61.2\% versus $38.8 \%)$. Most respondents (68\%) were 41-60 years old and the majority were from the Middle East (80.3\%). The largest number of respondents based on country came from the UAE $(\mathrm{n}=58)$ and Saudi Arabia $(n=25)$. Most respondents had medical and/or dental primary qualifications $(88.8 \%)$. There were more clinical and scientific professionals employed in healthcare than full-time academic university employees (70.7\% versus $29.3 \%$ ). The majority of the respondents had either a high postgraduate degree or a Board-type medical specialty certification ( $48.7 \%$ and $38.2 \%$, respectively) [Table 2]. Over half of the respondents (55\%) were practicing internal medicine and its related subspecialties whereas the remainder were evenly distributed over other specialities. English was the most frequently used language for professional communication followed by Arabic and French (81.5\%, 13.9\% and 4.6\%, respectively).

Almost two thirds (62.7\%) of the respondents had varying levels of publishing experience over the previous five years, mostly in international journals (77.9\%). The vast majority (83.3\%) of the published manuscripts were original studies [Table 3]. The most frequent themes of the publications were diabetes (35\%), endocrinology (15.4\%), paediatrics (7.7\%), pharmacology $(5.1 \%)$ and diseases (4.3\%).

The relative scoring of the impact of several attributes of scholarly journals on the authors' decision at the time of initial submission and second submission was cal- 


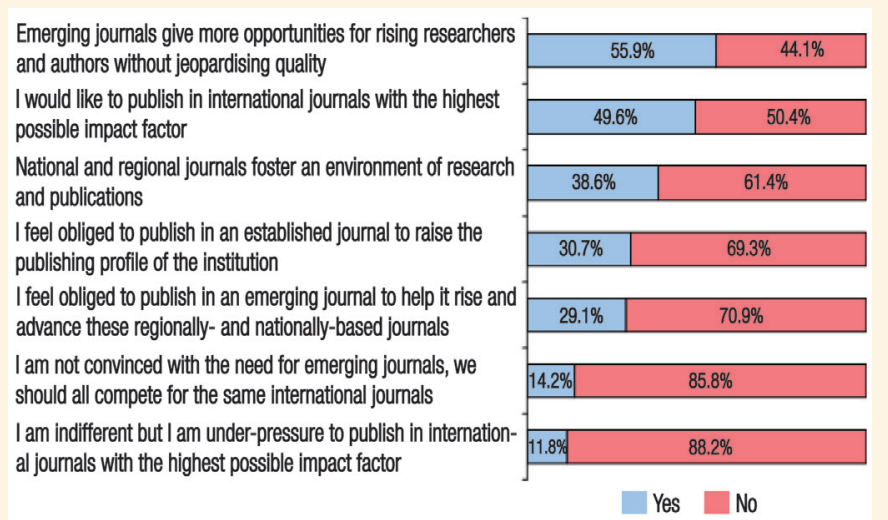

Figure 1: The attitudes of authors in the Middle East and Africa towards emerging journals $(\mathrm{N}=127)$.

\begin{tabular}{|c|c|c|}
\hline \multirow{2}{*}{$\begin{array}{l}\text { I browse and read certain emerging journals regularly } \\
\text { I have served as a peer reviewer for an emerging journal }\end{array}$} & $54.4 \%$ & $45.6 \%$ \\
\hline & $44.7 \%$ & $55.3 \%$ \\
\hline I have cited an article in an emerging journal at least once & $42.1 \%$ & $57.9 \%$ \\
\hline I have published in an emerging journal & $39.5 \%$ & $60.5 \%$ \\
\hline I served on an editorial board in an emerging journal & $22.8 \%$ & $77.2 \%$ \\
\hline I have been a managing editor of an emerging journal & $12.8 \%$ & $.2 \%$ \\
\hline
\end{tabular}

Figure 2: The encounters and practices of authors in the Middle East and Africa regarding emerging journals $(\mathrm{N}=114)$.

culated according to Equation 1 and is illustrated in Table 4. Indexation status, JIF, free submission and an international status were scored highly by respondents. Personally knowing the editor, size of journal circulation and likely readership and prestige were scored as unimportant factors in making a choice for submission [Table 4].

The majority (55.9\%) of respondents thought that emerging journals provide more opportunities for new researchers and authors without jeopardising quality. Some respondents (38.6\%) thought that national and regional journals foster an environment of research and less than one-third of the respondents (29.1\%) felt obliged to publish in an emerging journal to help advance regionally and nationally-based journals [Figure 1]. However, almost half of the respondents (49.6\%) still wish to publish in international journals and some (11.8\%) felt pressured to publish in international journals with the highest possible JIF, while others (30.7\%) felt obliged to do so to raise the publishing profile of their institution. A small proportion of respondents (14.2\%) stated that they were not convinced of the need for emerging journals and believed all authors should target the same international journals.

A total of 114 respondents reported their experiences with emerging journals. Over half of the respondents (54.4\%) regularly browse and read certain emerging journals, while less than half had served as a reviewer (44.7\%) or cited contents from emerging journals at least once (42.1\%). In addition, 39.5\% had published in an emerging journal while some had served in the editorial board or as managing editor of an emerging journal (22.8\% and 12.8\%, respectively) [Figure 2].

\section{Discussion}

This study showed that authors highly valued JIF, indexation status, free submission and an international status in their journal choice. Personal acquaintance with the journal editor, size of journal circulation and likely readership and prestige were considered to be unimportant factors. Søreide et al's study found that a journal's overall reputation, JIF and readership composition were important factors for journal choice for initial manuscript submissions. ${ }^{6}$ In Özçakar et al.'s study of authors who published in a surgical journal, the majority of respondents held the overall reputation of the journal as the most important factor followed by the JIF when choosing a journal for manuscript submission. ${ }^{7}$

Welch et al's study focused on European authors in physical medicine and rehabilitation and found that the three most important factors for journal choice were the area of interest (mission and contents) of the journal within their specialty, absolute JIF and a match between perceived quality of their research and the JIF. ${ }^{8}$ However, for many researchers prestige, a high JIF, 
journal reputation and an international journal status may not carry identical implications as in the current study. This makes direct comparison between studies difficult. ${ }^{6-8}$ For second submissions, the present study found no fundamental differences in deciding factors of journal choice from initial submissions. Other studies did not elucidate the differences between initial and second submissions. ${ }^{6-8}$

JIF is calculated by the average number of citations per article over a period of time, usually within a year. ${ }^{14-16}$ Whereas JIF assesses the impact of separately published articles, it is misused as an indication of the quality and scientific prestige of the journal as a whole. ${ }^{15}$ The JIF can also be distorted by several factors. Although JIF gives some information about the level of a journal's citations; they are generally poor indicators of journal quality, the quality of individual authors and their institutions. Several alternative metrics have been proposed as a better indicator of journal quality than JIF. ${ }^{14-16}$

Although journal indexation was valued highly by the respondents in the current study, it was not adequately considered in previous studies. ${ }^{6-8}$ However, many medical journals, publishing both internationally or locally, meet serious financial difficulties when attempting to be indexed internationally. ${ }^{17}$ This not only affects the scientific quality of non-indexed medical journals (NIMJs), but also affects the awareness of the scientific community on topics with apparently local but potentially broader scientific significance. This applies to many journals in the Middle East and Africa as well as many other regions.

The observed diverse range of attitudes regarding emerging journals is probably a reflection of the importance authors attach to indexation and JIF. Many genuine emerging journals require a long time to attain international indexation and to have a JIF calculated. However, the international scientific community is not indifferent to information published in NIMJs. ${ }^{17}$ Germenis et al. found that the medical community has expressed a special interest in this type of information. ${ }^{17}$ Some universities require their academic staff to publish in indexed journals and with a JIF of at least one. Consequently, authors who are not required by their institutions to submit to indexed journals may still support NIMJs until they are indexed. Therefore, universities should exercise some discretionary "positive discrimination" by exempting promising national and regional emerging journals to encourage university employees to publish in them, which may also diminish submissions to predatory journals. ${ }^{13,18}$

Journal editors, in regions where authors may not be fully aware of authorship rules and regulations, have more responsibilities in terms of an increased risk of inappropriate authorship, plagiarism and disputes. ${ }^{19-21}$ The low research productivity of developing nations reflects the lack for a strong research culture, which is complicated by low patient awareness of the value of research trials. ${ }^{22,23}$ Respondents in the present study were cost-conscious; they ranked free submission highly perhaps due to lack of support of their employers to open access journals, but they do not seem to be influenced by free access [Table 4]. This differs from Schroter et al's study which showed that authors valued free access to their research articles and considered dissemination to be an important factor in deciding to which journal to submit. ${ }^{24}$ Genuine emerging journals are normally open access for both authors and readers. ${ }^{9}$

The current study observed a diverse range of attitudes regarding emerging journals. The reported actual experiences with emerging journals were low. These findings should help emerging journals to better address the needs of future authors, which will increase their value and help protect authors from predatory journals. ${ }^{10,18}$ Alsanea et al. used a root-cause analysis of the workflow process and output of a major Saudi Arabian journal and showed that the substantial amount of published case reports affected its JIF. ${ }^{25}$ In addition, a slow review process due to the poor response of reviewers was a problem that many emerging journals face. ${ }^{9,10,25}$

The current study is limited by its sample size, convenience sampling method and that about one third of the respondents had no previous publishing experience. However, this is the first study of its nature from the Middle East and Africa on this topic and its findings can provide regional editors with important insights into the views of their potential authors.

\section{Conclusion}

The present study demonstrated that several factors influence authors' choice of journals for publication; however, the financial factor had a unique effect on authors' choice from the Middle East and Africa. This studyfounddifferencesintheattitudesofauthorstowards emerging journals. Editors and publishers of emerging journals may benefit from these results to make their journals more attractive to potential authors. Emerging journals need to adapt and maintain the highest quality of scholarly publishing to be indexed internationally and to meet the expectations of their potential authors.

\section{CONFLICT OF INTEREST}

The author declares no conflicts of interest.

\section{FUNDING}

No funding was received for this study. 


\section{References}

1. Dhammi IK, Haq RU. Submission to publication demystified: A guide for authors. Indian J Orthop 2017; 51:631-2. https://doi. org/10.4103/ortho.IJOrtho_599_17.

2. Peh WC, Ng KH. Preparing a manuscript for submission. Singapore Med J 2009; 50:759-61.

3. Caon M. Choosing the appropriate peer-reviewed journal for submission of your manuscript. Australas Phys Eng Sci Med 2018; 41:779-80. https://doi.org/10.1007/s13246-018-0687-y.

4. Bavdekar SB, Save S. Choosing the right journal for a scientific paper. J Assoc Physicians India 2015; 63:56-8.

5. Frank E. Authors' criteria for selecting journals. JAMA 1994; 272:163-4. https://doi.org/10.1001/jama.1994.03520020089026.

6. Søreide K, Winter DC. Global survey of factors influencing choice of surgical journal for manuscript submission. Surgery 2010; 147:475-80. https://doi.org/10.1016/j.surg.2009.10.042.

7. Özçakar L, Franchignoni F, Kara M, Muñoz Lasa S. Choosing a scholarly journal during manuscript submission: The way how it rings true for physiatrists. Eur J Phys Rehabil Med 2012; 48:643-7.

8. Welch SJ. Selecting the right journal for your submission. Thorac Dis 2012; 4:336-8. https://doi.org/10.3978/j.issn.20721439.2012.05.06.

9. Beshyah SA, Elkhammas EA. Manuscript peer review for emerging journals: Where we go from here? Ibnosina J Med Biomed Sci 2015; 7:155-7. https://doi.org/10.4103/1947-489X.210280.

10. Beshyah SA, Aburawi EH, Alshammakhi N, Elkhammas EA. Why should you publish in Ibnosina Journal of Medicine and Biomedical Sciences? Ibnosina J Med Biomed Sci 2017; 9:99-100. https://doi.org/10.4103/ijmbs.ijmbs_5_17.

11. Piterman L, McCall L. Targeting the right journal. Aust Fam Physician 1999; 28:730-1.

12. Badenhorst B, Mansoori P, Chan KY. Assessing global, regional, national and sub-national capacity for public health research: A bibliometric analysis of the Web of Science(TM) in 19962010. J Glob Health 2016; 6:010504. https://doi.org/10.7189/ jogh.06.010504.

13. Beshyah SA. Predatory publishing: A wake-up call for editors and authors in the Middle East and Africa. Ibnosina J Med Biomed Sci 2017; 9:123-5. https://doi.org/10.4103/ijmbs.ijmbs_26_17.

14. van Driel ML, Magin PJ, Del Mar CB, Furler J, De Maeseneer J. Journal impact factor and its importance for AFP. Aust Fam Physician 2008; 37:770-3.
15. Bornmann L, Marx W, Gasparyan AY, Kitas GD. Diversity, value and limitations of the journal impact factor and alternative metrics. Rheumatol Int 2012; 32:1861-7. https://doi.org/10.1007/s00296-0112276-1.

16. Huggett $\mathrm{S}$. Journal bibliometrics indicators and citation ethics: A discussion of current issues. Atherosclerosis 2013; 230:275-7. https://doi.org/10.1016/j.atherosclerosis.2013.07.051.

17. Germenis AE, Kokkinides PA, Stavropoulos-Giokas C. Nonindexed medical journals in the web: New perspectives in the medical literature. Int J Med Inform 1997; 47:65-8. https://doi. org/10.1016/S1386-5056(97)00076-2

18. Beshyah SA, Hajjaji IM, Elbarsha A. Awareness of predatory journals among physicians from Africa and the Middle East: An exploratory survey. Ibnosina J Med Biomed Sci 2018; 10:136-40. https://doi.org/10.4103/ijmbs.ijmbs_45_18.

19. Ismail KH. Perceptions of plagiarism among medical and nursing students in Erbil, Iraq. Sultan Qaboos Univ Med J 2018; 18:e196-201. https://doi.org/10.18295/squmj.2018.18.02.012

20. Beshyah SA, Ibrahim WH, Aburawi EH, Elkhammas EA. The rules and realities of authorship in biomedical journals: A cautionary tale for aspiring researchers. Ibnosina J Med Biomed Sci 2018; 10:149-57. https://doi.org/10.4103/ijmbs.ijmbs_62_18.

21. Beshyah SA, Abdelmannan DK, Elzouki AN, Elkhammas EA Authorship disputes: Do they result from inadvertent errors of judgment or intentional unethical misconduct? Ibnosina J Med Biomed Sci. 2018; 10:158-65. https://doi.org/10.4103/ijmbs.ijm bs_58_18.

22. Algahtani H, Shirah B, Boker F, Algamdi A, Alkahtani A. Neurology research in Saudi Arabia: Urgent call for action. Sultan Qaboos Univ Med J 2017; 17:e324-8. https://doi.org/10.18295/ squmj.2017.17.03.011.

23. Al-Lawati $\mathrm{H}, \mathrm{Al}$-Baimani $\mathrm{K}, \mathrm{Al}$-Zadjali $\mathrm{M}, \mathrm{Al}$-Obaidani $\mathrm{N}$, Al-Kiyumi Z, Al-Khabori MK. Knowledge and attitudes towards clinical trial participation in Oman: A cross-sectional study. Sultan Qaboos Univ Med J 2018; 18:e54-60. https://doi.org/10.18295/ squmj.2018.18.01.009.

24. Schroter S. Importance of free access to research articles on decision to submit to the BMJ: Survey of authors. BMJ 2006; 332:394-6. https://doi.org/10.1136/bmj.38705.490961.55.

25. Alsanea N, Al-Ghammas A, Pangan-Menor J, Tejano RV, Al-Bassam N, Duero-Ebora J, et al. The obstacles facing scientific and medical publishing in Saudi Arabia. Ann Saudi Med 2014; 34:202-6. https://doi.org/10.5144/0256-4947.2014.202. 